\title{
Teoria das Representações Sociais: a Ruptura de Paradigmas das Correntes Clássicas das Teorias Psicológicas
}

Social Representations Theory: the Breaking of Paradigms of the

Classic Trends of the Psychological Theories

La Teoría de las Representaciones Sociales: la Ruptura de Paradigmas de las Corrientes Clásicas de las Teorías Psicologicas

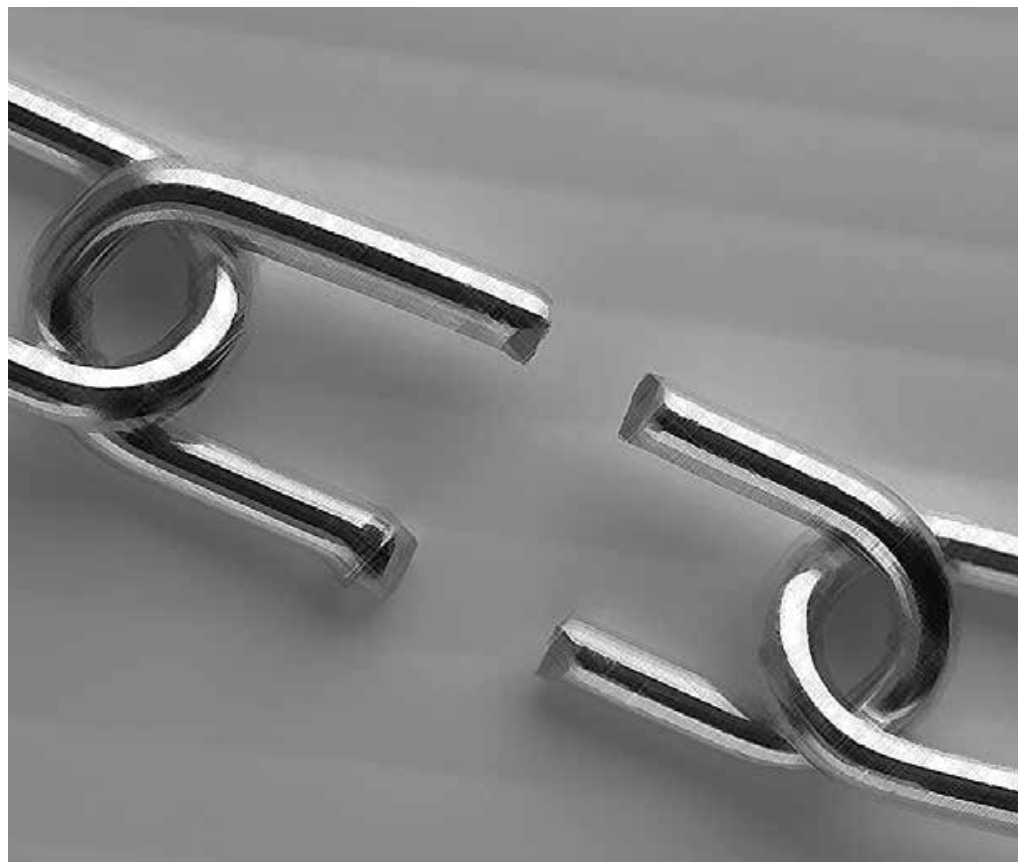


Resumo: A teoria das representações sociais é o principal objetivo deste artigo de revisão bibliográfica, cujo estudo se inicia com a discussão dos paradigmas científicos predominantes e de como a teoria se encontra em uma posição de rompimento com esses paradigmas. Desenvolvida sob a necessidade de se construir uma Psicologia social que superasse a dicotomia indivíduo e sociedade, a teoria abarca uma série de objetos que dizem respeito à comunicação e à elaboração de comportamentos entre indivíduos e grupos. O texto também traz críticas à teoria, particularmente no tocante à sua relação com o conceito de ideologia, proposta por diversos autores. De todo modo, a fecundidade de seus conceitos e o amplo uso a que pode ser submetida tornam a teoria das representações sociais importante construto, não somente para a Psicologia como também para as disciplinas das áreas de humanidades.

Palavras-chave: Representação social. Paradigma. Psicologia. Psicologia social.

Abstract: The social representations theory is the main objective of this bibliographical review paper, that initiates by the discussion of the prevailing scientific paradigms and also how the theory in question remains in a position of rupture with these paradigms. Developed under the need of building a social psychology that outperformed the individual and society dichotomy, the theory includes an amount of objects concerning the communication and the elaboration of behavior among individuals and groups. The text also criticizes the theory, particularly concerning to its relationship with the concept of ideology, proposed by several authors. Anyhow, the fecundity of its concepts and the wide use that it can be submitted to make the social representations theory an important construct not only for psychology, but also for the disciplines of the humanity area.

Keywords: Social representation. Paradigm. Psychology. Social psychology.

Resumen: La teoría de las Representaciones Sociales es el objetivo de esta revisión de la literatura, cuyo estudio comienza con un análisis de los paradigmas científicos y cómo la teoría que prevalece en cuestión se encuentra en condiciones de romper con ellos. Desarrollado bajo la necesidad de construir una psicología social que supere la dicotomía entre individuo y sociedad, la teoría abarca una serie de objetos con respecto a la comunicación y el comportamiento de los individuos y grupos. El texto tras también la teoría crítica, especialmente con respecto a su relación con el concepto de ideología, propuesta por diversos autores. De todos modos, la fertilidad de sus conceptos y el uso generalizado que se pueden presentar convertido en la teoría de las representaciones sociales construyen no sólo es importante para la psicología como para las disciplinas de las humanidades.

Palabras clave: Representación sociale. Paradigma. Psicología. Psicología social.

\section{A produção do conhecimento}

(...) O espírito científico é essencialmente uma justificação do saber, um alargamento dos quadros do conhecimento. Julga seu passado histórico, condenando-o. Sua estrutura é a consciência de suas faltas históricas. Cientificamente, pensa-se o verdadeiro como retificação histórica de um longo erro, pensa-se a experiência como a retificação da ilusão comum e primeira. Toda a vida intelectual da ciência move-se dialeticamente sobre essa diferencial do homem, na fronteira do desconhecido. A própria essência da reflexão é compreender que não se compreenderá (Bachelard, 1968, pp. 147-148)

Em razão da situação existencial do ser humano no mundo, surge a necessidade de desvelar esse mundo, de conhecê-lo, e, para isso, o ser humano precisa interpretar a si próprio e ao mundo em que vive, atribuindoIhe significados. Na busca de seu mister, o ser humano cria intelectualmente reproduções significativas da realidade que podem ser chamadas de conhecimento (Köche, 1997). Dependendo da forma como se chega a essa representação significativa, o conhecimento é classificado em diversos tipos: empírico, filosófico, teológico, artístico e científico (Köche, 1997; Cervo \& Bervian, 1996).

O senso comum, conhecimento ordinário ou empírico é a forma mais utilizada pelo homem na busca da representação significativa (Köche, 1997). O conhecimento empírico é também denominado conhecimento vulgar, do povo, pois é obtido ao acaso, de forma ametódica e assistemática (Cervo \& 
A ciência pode ser considerada um outro mundo, artificial, construído sobre o mundo físico e emocional do ser humano, e seria uma tentativa de reconstrução do mundo e do ser humano por meio de termos simbólicos e conceituais (Moreira, 2002).

1“Doutrina que afirma a relatividade do conhecimento, no sentido dado a essa expressão no séc. XIX, a saber: I. como ação condicionante do sujeito sobre seus objetos

de conhecimento; 2 . como ação condicionante recíproca dos objetos de conhecimento" (Abagnano, 1988, p. 845).
Bervian, 1996). De acordo com Köche, "esse conhecimento surge como conseqüência da necessidade de resolver problemas imediatos, que aparecem na vida prática e decorrem do contato direto com os atos e fenômenos que vão acontecendo no dia a dia, percebidos principalmente através da percepção sensorial" (1997, p. 24).

A necessidade de o ser humano não assumir uma posição meramente passiva, de espectador dos fenômenos, sem ação e controle sobre eles, faz surgir o conhecimento científico, que vai além do empírico e busca conhecer não só o fenômeno como também suas causas e leis (Cervo \& Bervian, 1996).

A ciência pode ser considerada um outro mundo, artificial, construído sobre o mundo físico e emocional do ser humano, e seria uma tentativa de reconstrução do mundo e do ser humano por meio de termos simbólicos e conceituais (Moreira, 2002). Severino afirma que

a ciência, como modalidade de conhecimento, só se processa como resultado de articulação do lógico como real, do teórico ao empírico. Não se reduz a um mero levantamento e exposição de fatos a uma coleção de dados. Estes precisam ser articulados mediante uma leitura teórica. Só a teoria pode caracterizar como científicos os dados empíricos. Mas, em compensação, ela só gera ciência se estiver articulando dados empíricos (2000, p. 149)

Acrescente-se assim que, para a construção de conhecimento científico, faz-se necessário não apenas pesquisar, em sentido estrito, mas, em sentido amplo, explorar o objeto de conhecimento, expondo-o e correlacionando-o aos paradigmas epistemológicos e teóricos existentes e aceitos pela comunidade científica.

Para que ocorra tal produção de conhecimento, há um leque de perspectivas de investigação que se enquadram nas diversas visões existentes do aspecto social, entre as quais se destacam o positivismo, o interpretativismo, a ciência social crítica e o relativismo ${ }^{1}$. Em outras palavras, há vários paradigmas ou perspectivas paradigmáticas, que estão, deliberadamente ou não, subjacentes às abordagens de investigação.

Nesse sentido, é importante que o pesquisador conheça e compreenda, de acordo com sua perspectiva e suas necessidades, e de forma adequada ao seu objeto, o referencial teórico que lhe dará suporte para transformar e analisar os dados obtidos em informação. Isso distingue a pesquisa de um simples amontoado de dados e de informações meramente descritivas, exigindo, igualmente, e tendo como critério de validação, a análise de tais dados.

Cabe sublinhar que o conhecimento dos referenciais teóricos ou paradigmas tem se tornado cada vez mais dificultoso para o pesquisador, pois os questionamentos aos pressupostos e procedimentos - que desde muito orientavam as atividades científicas e conferiam credibilidade aos seus resultados são cada vez mais constantes e avassaladores, não só no que tange à própria ciência mas também a outras áreas do conhecimento, como a Filosofia, a religião e a arte.

Destarte, frise-se que, na escolha do referencial, o importante é a adequação ao que se pretende investigar. Contudo, isso não significa um verdadeiro vale tudo, sob o pretexto de que a minha lente, o meu olhar, seja o melhor, julgando-se poder prescindir de evidências e de argumentação sólida.

A falácia do vale tudo encontra resistência na necessidade de validação dos resultados diante do paradigma escolhido e da argumentação sólida, exigindo, segundo Severino, “(...) além do referencial epistemológico preciso e rigoroso, capacidade de domínio e manuseio 
de um conjunto de métodos e técnicas específicos de cada ciência" (1996, p. 58). Desse modo, é essencial a aplicação de métodos e de técnicas de investigação adequados aos objetos pesquisados (Severino, 2002).

O princípio fundamental para o pesquisador, em seus trabalhos, é a consciência de que ele se encontra em processo de construção do conhecimento. Guareschi observa que

Ninguém possui uma compreensão total de todas as coisas, nem mesmo a compreensão total de uma única coisa. Vamos arranhando as coisas passo a passo, momento a momento, descobrindo novos sentidos, ampliando compreensões, penetrando mais a fundo no seu mistério (2003, p. 245)

O objetivo de todos é alcançar a verdade, porém, nenhum mortal é seu dono. A representação das coisas e dos objetos que o homem busca conhecer se oculta e se manifesta sob múltiplas formas. Nem sempre aquilo que se manifesta, que aparece em dado momento, é a totalidade do objeto, da realidade investigada (Cervo \& Bervian, 1996). Segundo Ferreira, Calvoso e Gonzales,

questionamos uma concepção de verdade com caráter transcendental e absoluto. Os critérios de verdade são construções, contingentes e determinados pelas práticas sociais, convencionados socialmente e sofrem modificações constantes em função das próprias transformações sofridas pelos grupos sociais (2002, p. 248)

Mesmo diante de todos os fatores que influenciam na investigação, sejam individuais, sejam sociais ou estruturais do fenômeno, sejam, ainda, as características individuais, psicológicas, das pessoas envolvidas - sujeito, pesquisador -, o investigador jamais pode perder de vista o objeto da pesquisa. Segundo Guareschi (2003), o mais importante é que sempre se examine o objeto.
As correntes predominantes na ciência moderna baseavam-se no racionalismo e no positivismo, sustentadas nos ideais de experimentação e de quantificação, no rigor das medições. A ausência de quantificação e de experimentação do resultado não possuía reconhecimento científico.

As regras metodológicas e os pressupostos epistemológicos são rígidos, constituindo-se, conforme Santos, em "(...) um conhecimento causal que inspira a formulação de leis, à luz de regularidades observadas, com vistas a prever o comportamento futuro dos fenômenos" (Santos, 1988, p. 51). Assim, o avanço e o sucesso na ciência moderna decorrem de um método rigoroso e universalizante, independentemente das contingências temporais e culturais.

Em contraposição à tradição da ciência moderna, para Kuhn (1975), a ciência não se desenvolve por meio da obediência rígida aos preceitos metodológicos, mas sim, por ser conduzida à luz de um paradigma. $\mathrm{O}$ conceito central da reconstrução da racionalidade científica baseia-se no paradigma.

Segundo Kuhn, os paradigmas devem ser compreendidos como um conjunto de teorias e princípios sobre a estrutura de determinada matéria, que são consensuais e indiscutíveis pela comunidade científica. A principal função desempenhada pelo paradigma consiste em estabelecer o consenso em determinada comunidade científica, com a delimitação dos fatos relevantes e a apresentação dos métodos adequados de abordagem e das soluções legítimas.

A maioria dos avanços científicos funda-se na concepção do modo cumulativo, ou seja, dentro de padrões previamente estabelecidos que são somados ao acervo do conhecimento científico. Contudo, Kuhn (2006) propõe um desenvolvimento científico denominado revolucionário, isto é, aquele que compreende 
um modo não cumulativo, que se baseia em salto, em rupturas profundas que não podem ser acomodadas nos limites dos conceitos utilizados anteriormente a elas, e que exigem mudança no modo de pensar, na visão de mundo.

Tal mudança, de acordo com o autor, envolve “(...) uma transformação relativamente súbita e não estruturada na qual alguma parte do fluxo da experiência se arranja de maneira diferente e exibe padrões que antes não eram visíveis" (Kuhn, 2006, p. 28). Essas rupturas ou mudanças revolucionárias proporcionam o avanço do desenvolvimento científico de forma a atingir todos os níveis de conhecimento acerca de determinado objeto, revelando, muitas vezes, a distorção da linguagem científica anteriormente posta, não problematizada, tornando-se esta, como observa Kuhn, a "(...) pedra de toque para a mudança revolucionária” (2006, p. 45).

Na imagem de ciência proposta pelo autor (1975, 2006), seu desenvolvimento ocorre através de fases sucessivas, e a primeira delas é a pré-paradigmática - mais adequadamente denominada multiparadigmática (Mendonça \& Videira, 2002) -, em que várias escolas competem entre si, buscando um acordo sobre questões fundamentais, em que cientistas de comunidades diferentes tentam persuadir uns aos outros da superioridade dos princípios envolvidos em suas pesquisas. Nas ciências sociais, por seu turno, não há um consenso paradigmático, motivo pelo qual a discussão tende a atravessar verticalmente toda a espessura do conhecimento adquirido (Santos, 1988).

Conforme Kuhn, as ciências sociais são consideradas pré-paradigmáticas, o que explica o atraso dessas ciências em relação às ciências naturais, pois, nas ciências sociais, ainda não se tornou possível desenvolver o conhecimento por meio da formulação de um conjunto de princípios e de teorias sobre a estrutura da matéria, aceitos sem oposição em toda a comunidade científica. Ao lado de Kuhn, como um dos principais expoentes da Nova Filosofia da Ciência, temos também Feyerabend, entre outros ${ }^{2}$. Esse autor (2007) - defendendo a ideia de que nenhuma metodologia pode ser definitiva, ou inflexível, uma vez que há um labirinto de interações que implica a necessidade de flexibilidade e, muitas vezes, de violação dos métodos existentes - instituiu o anarquismo metodológico, incitando à violação do método, baseado no desenvolvimento científico demonstrado através da História.

Tanto Kuhn como Feyerabend valorizam a História como peça fundamental no desenvolvimento científico, pois, segundo Feyerabend (2007), além de a violação do método ser algo necessário e normal, para o desenvolvimento da ciência, uma teoria que se apresente de forma equivocada, hoje, pode ser considerada a mais acertada amanhã, de forma que o progresso científico não pode ser prejudicado pelo dogmatismo metodológico exacerbado. Apesar de romper com o contexto e com o dogmatismo metodológico vigentes em sua época, Feyerabend manteve como fios condutores de suas ideias a crítica à hegemonia e ao humanismo liberal.

Para esse autor, o monismo teórico pode levar à hegemonia ao estabelecer a verdade, ocorrendo a inibição da variedade inerente ao potencial humano e ao exercício da liberdade de escolha, desconsiderando-se, portanto, uma questão essencial, qual seja, a falibilidade humana. O filósofo evidencia, ainda, a necessidade de pluralidade teórica e de uma base ética humanista para a epistemologia.

A utilização de diversos métodos possíveis de emprego e/ou de uso concomitante desses métodos leva ao relativismo das verdades, uma vez que elas podem variar de acordo com o(s) método(s) utilizado(s). AlvesMazzotti e Gewandsznajder observam que 
falar sobre ciência e conhecimento científico atualmente constitui uma tarefa difícil. Novos paradigmas, gerados tanto no âmbito da própria ciência como em outras áreas do conhecimento, vêm questionando pressupostos e procedimentos que até então orientavam a atividade científica e conferiam credibilidade aos seus resultados (...) (2002, p. 109)

Em razão do desenvolvimento científico e dos questionamentos dos pressupostos e dos procedimentos até então existentes e intocáveis, das rupturas com o positivismo e com os dogmas metodológicos existentes e instransponíveis, os quais já não satisfazem mais as necessidades existentes, falar sobre ciência e conhecimento científico hoje tornou-se uma tarefa difícil.

A necessidade de superação das questões metodológicas, na produção do conhecimento em Psicologia, visando principalmente ao enfrentamento da problemática que envolve as dicotomias sujeito/objeto, indivíduo/ sociedade e individual/social, tem sido objeto de estudo e de reflexões de pesquisadores e teóricos, ao longo de várias décadas.

Conforme se verá a seguir, a teoria das representações sociais constitui uma tentativa de ruptura com as correntes clássicas das teorias psicológicas e uma das alternativas para explicar e entender o psiquismo humano, visando sobretudo ao enfrentamento da problemática que envolve as dicotomias sujeito/objeto e indivíduo/ sociedade.

\section{A teoria das representações sociais}

As representações são criadas pelos seres humanos para que eles apreendam o mundo à sua volta, pela necessidade de comportamento, informação, domínio físico e intelectual do mundo. As representações são sociais porque o mundo é partilhado entre as diversas pessoas que o compõem, que servem de apoio umas para as outras, muitas vezes de forma convergente, outras de forma conflituosa, para compreendê-lo, administrá-lo ou enfrentá-lo (Jodelet, 2001). Conforme Souza,

representar é uma capacidade mental inerente ao homem que busca apreender a realidade que o rodeia. Pode-se perceber essa capacidade representativa através da linguagem falada e escrita, nos comportamentos, na produção pictórica e gráfica que nos cercam. Em síntese, pode-se afirmar que representar são formas que traduzem o querer, o sentir e o agir humanos (2005, p. 61)

A relação dialética estabelecida pelo homem entre os aspectos individual e social é a base teórica do conceito de representação social, ou seja, da apropriação da realidade social pelo indivíduo, de modo que o social e o exterior se tornam internos.

Como uma das alternativas para tentar explicar e entender o psiquismo humano - visando, em especial, ao enfrentamento da problemática que envolve as dicotomias sujeito/objeto e indivíduo/sociedade -, foi elaborada, na década de 60, a teoria das representações sociais, idealizada pelo sociólogo Serge Moscovici (1978), na França, com o trabalho intitulado La Psychanalyse, son Image et son Public (1961), no qual o autor propõe a socialização da psicanálise e também uma forma sociológica de Psicologia social (Farr, 2009; Sá, 1995).

O nascimento da teoria das representações sociais ocorreu em um período histórico marcado por mudanças provocadas pela insatisfação e pela tentativa de superação do modelo científico que valorizava de forma excessiva os saberes científicos em detrimento da cultura do senso comum, menosprezando e desprestigiando o valor das crenças e dos conceitos culturalmente construídos no intercâmbio comunicacional cotidiano que constitui e é constituído na cultura. 
A insatisfação do modelo científico vigente também alcançou o modelo tradicional da Psicologia, de natureza positivista, vinculada às ciências naturais, de caráter individualista, instaurando um movimento de ressignificação daquela ciência, cuja matériaprima é a cultura (Souza, 2005).

Em seus estudos iniciais, Moscovici (1978) resgatou historicamente o conceito de representações, buscando renovar e confirmar a especificidade da Psicologia social, com base em estudos que pudessem explicar como se dá a relação entre os âmbitos individual e social, negando, pois, explicações estritamente sociais, como em Durkheim, ou as essencialmente cognitivas, como em Piaget.

A origem da teoria das representações sociais está relacionada com a sociologia de Durkheim e com a antropologia de Lévy-Bruhl, porque Moscovici buscava a transformação da perspectiva individualista que se encontrava instalada na Psicologia social tradicional, rompendo os paradigmas então existentes.

Para Moscovici (1985), o dualismo entre o mundo individual e o mundo social provocava repulsa, uma vez que sua intenção era desenvolver uma psicossociologia do conhecimento que levasse em consideração tanto os elementos individuais quanto os fatos sociais, sendo essencial, segundo Sá, a influência dos contextos sociais não somente nos comportamentos individuais mas também na construção das próprias realidades sociais.

Durkheim (1895 como citado em Jodelet, 2001) foi o primeiro a identificar e a estudar os objetos e os elementos das representações sociais como produções mentais, extraídos de um estudo sobre a ideação coletiva. Contudo, a perspectiva durkheimiana despreza qualquer explicação psicológica para os fatos sociais.
Inicialmente, as representações sociais, como foram estudadas por Durkheim (1978), chamaram-se representações coletivas, o que serviu como elemento básico para elaborar uma teoria da religião, da magia e do pensamento mítico. Contribuíram, ainda, para a criação da teoria das representações sociais, a teoria da linguagem, de Saussure, a teoria das representações infantis, de Piaget, e a teoria do desenvolvimento cultural, de Vigotsky.

Salienta Moscovici (2009) que o conceito de representação social complementou a teoria de Durkheim, Lévy-Bruhl e Mauss, que dele careciam. Enfatiza ainda o psicossociólogo que o conceito de representação social foi uma tarefa importante para a Psicologia social, pois ela procura renovar e confirmar a especificidade da Psicologia social, que, na perspectiva desse autor, é difícil de se estabelecer.

Spink (1995) argumenta que, para Durkheim, as representações coletivas, em relação ao comportamento e ao pensamento individuais, são resultado da cooperação estabelecida tanto no espaço quanto no tempo, em cujas redes várias gerações acumularam experiência e saber.

Moscovici renovou a análise de Durkheim “(...) insistindo sobre a especificidade dos fenômenos representativos nas sociedades contemporâneas, caracterizadas por: intensidade e fluidez das trocas e comunicações, desenvolvimento da ciência, pluralidade e mobilidades sociais" (Jodelet, 2001, p. 22), buscando o desenvolvimento de uma psicossociologia do conhecimento e instaurando uma redefinição para os problemas e conceitos até então existentes na Psicologia social. Souza ressalta que,

na Psicologia social, as representações ganham um sentido para além da apreensão e conceituação, pois são sistemas mentais também criativos, autônomos e que 
Segundo Guareschi (1996), por meio do conceito de relação, ou seja, pela compreensão de que os objetos, a sociedade, a vida social, o ser humano, tudo o que existe, se constitui mediante relações, a teoria das representações sociais estabelece uma síntese entre o individual e o social, o interno e o externo, o estático e o dinâmico, a gênese e a estrutura, $\mathrm{O}$ consistente e o mutável, o material e o simbólico. constroem o real. Nesse modelo, a representação não é só resultado da ação mental, mas sim, motivadora da mesma, sendo também vista como eminentemente social em suas origens e função (2005, p. 62)

Ao retornar ao conceito de representações de Durkheim, Moscovici não o fez simplesmente sob uma perspectiva crítica, mas tinha uma intenção construtiva: proporcionar à Psicologia social objetos e instrumentos conceituais que permitissem um conhecimento cumulativo, diretamente com as verdadeiras questões colocadas na vida social (Jodelet, 2001).

Para Moscovici (2003), o importante não é conhecer as representações de um passado remoto, de sociedades primitivas, mas as presentes, do tempo atual da sociedade, considerando-se que o conhecimento produzido é relativo a quem fala e de onde fala, a qual grupo pertence, e não ao objeto em si, salientando a importância do grupo de pertencimento.

Segundo Guareschi (1996), por meio do conceito de relação, ou seja, pela compreensão de que os objetos, a sociedade, a vida social, o ser humano, tudo o que existe, se constitui mediante relações, a teoria das representações sociais estabelece uma síntese entre o individual e o social, o interno e o externo, o estático e o dinâmico, a gênese e a estrutura, o consistente e o mutável, o material e o simbólico.

Segundo Jodelet, em razão dos vários significados, as representações expressam determinado indivíduo ou determinado grupo, “(...) que as forjam e dão uma definição específica ao objeto por elas representado" (2001, p. 20).

Contudo, não se pode desprezar o fato de que esse processo ocorre sob o peso da tradição, da memória, do passado. Isso não significa, porém, que estejam sendo criados e acrescentados novos elementos à realidade consensual, que não esteja ocorrendo a produção de mudanças no sistema de pensamento, que não se esteja dando prosseguimento à construção do mundo de ideias e de imagens em que vivemos (Spink, 1995). Constantino, Eloy, Quadrini e Macedo destacam que

as transformações do homem e a forma como assimila a realidade social são percebidas pela teoria das representações sociais em um processo histórico e não natural, considerando a ideologia como determinante de formas de pensar e agir. A ideologia integra também essas representações e influencia diretamente na consciência individual, em que se identificam e se localizam. De acordo com Salles (1991), a ideologia se concretiza em nível de representações sociais, e é expressa no exterior, no mundo, pelas ações e linguagem dos homens (2007, p. 54)

Em Jodelet (como citado em Jovchelovitch, 2000, p. 41), a teoria das representações sociais possui caráter tanto referencial como construtivista, pois as representações sociais são sempre a representação de um objeto, “(...) elas ocupam o lugar de alguma coisa, elas re-apresentam alguma coisa". Jodelet (1984), como citado em Jovchelovitch, explica que,

dessa forma, elas representam, por
excelência, o espaço do sujeito social,
lutando para dar sentido, interpretar e
construir o mundo em que ele se encontra.
Para além das estruturas dadas da vida
social, elas oferecem a possibilidade da
novidade, da autonomia, daquilo que
ainda não existe, mas que poderia existir.
Elas são, nesse sentido, uma relação do
ausente e um meio de evocar o possível
(2000, p. 41)

As representações sociais vão além de atitudes e imagens, possuindo a função de constituir a realidade, e são, ao mesmo tempo, a marca, o sinal e a reprodução de um objeto socialmente valorizado, significando sempre a reprodução de alguém sobre alguma coisa, conforme salientado por Menin (2000). 
O instrumento utilizado pelos indivíduos para atribuir significação às suas realidades é a linguagem, de sorte que essa significação é a representação social, que é produzida de forma coletiva pela sociedade. O indivíduo labora em um processo de apropriação das significações historicamente produzidas pela sociedade, transformando-as de acordo com suas necessidades e particularidades psíquicas, objetivando-as como parte de seu pensamento cotidiano, presentes os aspectos culturais, cognitivos e valorativos.

Jovchelovitch afirma que Jodelet discute o conceito da representação social e o seu desenvolvimento em uma “(...) teoria a partir do que uma representação é", ressaltando que o ato da representação é essencial para construir a representação social:

Ela argumenta que o ato da representação supera as divisões rígidas entre o externo e o interno ao mesmo tempo em que envolve um elemento ativo de construção e re-construção; o sujeito é autor da construção mental e ele a pode transformar na medida em que se desenvolve. Sua análise do ato da representação também delimita cinco características que vêm a ser fundamentais na construção das representações sociais..., o fato de que elas sempre são a referência de alguém para alguma coisa, seu caráter imaginativo e construtivo, que a faz autônoma e criativa e, finalmente, sua natureza social, o fato de que 'os elementos que estruturam a representação advêm de uma cultura comum e esses elementos são aqueles da linguagem' (2009, p. 76)

As representações sociais são encontradas nas reuniões públicas, nos cafés, nas ruas, nos meios de comunicação, nas instituições sociais, enfim, no encontro público de atores sociais, nos espaços em que os sujeitos sociais se reúnem para falar e dar sentido ao cotidiano (Jovchelovitch, 2000).

Na perspectiva de Moscovici, há um poder criador de objetos e de eventos da nossa atividade representativa, há “(...) relações entre o nosso reservatório 'de imagens e a nossa capacidade de combiná-las, de engendrar novas e surpreendentes combinações'" (2003, p. 48). O autor acrescenta:

(...) A representação constitui uma preparação para a ação, pois, além de guiar o comportamento, ela remodela e reconstitui os elementos do meio ambiente em que o comportamento deve se ligar. Ela consegue incutir um sentido ao comportamento, integrá-lo numa rede de relações em que está vinculada ao seu objeto, fornecendo ao mesmo tempo as noções, as teorias e os fundos de observação que tornam essas relações estáveis e eficazes (2003, p. 49)

Moscovici ainda ressalta que "(...) uma representação fala tanto quanto mostra, comunica tanto quanto exprime", e, concluindo sobre o conceito de representação social, afirma que a representação social “(...) é uma modalidade de conhecimento particular que tem por função a elaboração de comportamentos e a comunicação entre indivíduos" (1978, p. 26). Conforme Wagner,

de um lado, a representação social é concebida como processo social que envolve comunicação e discurso, ao longo do qual significados e objetos sociais são construídos e elaborados. Por outro lado, (...) as representações sociais são operacionalizadas como atributos individuais - como estruturas individuais de conhecimento, símbolos e afetos distribuídos entre as pessoas em grupo ou sociedades (2009, p. 149)

O termo representação social é multifacetário, já que designa tanto um conjunto de fenômenos quanto o conceito que os engloba e a teoria que os explica (Sá, 1995), ou seja, ele pode ser concebido como teoria, categoria explicativa ou analítica ou como conceito (Moreira \& Oliveira, 1998).

\section{Contextualização da teoria das representações sociais}

Como já se frisou, a teoria das representações sociais foi idealizada na França, na década 
de 60, por Serge Moscovici, sociólogo com doutorado em Psicologia Social. Essa teoria apresenta-se como uma das alternativas para tentar explicar e entender o psiquismo humano no enfrentamento da problemática que envolve as dicotomias sujeito/objeto e indivíduo/sociedade.

Para Farr (2009), a teoria das representações sociais é uma forma sociológica de Psicologia social, diferindo marcadamente das formas psicológicas/individualistas da Psicologia social, especialmente daquelas predominantes na Europa e nos Estados Unidos. De acordo com Jovchelovitch,

(...) a teoria das representações sociais se articula tanto com a vida coletiva de uma sociedade como com os processos de constituição simbólica, nos quais os sujeitos sociais lutam para dar sentido ao mundo, entendê-lo e nele encontrar seu lugar, através de uma identidade social. Isso significa deixar claro como as representações sociais, enquanto fenômeno psicossocial, estão necessariamente radicadas no espaço público e nos processos através dos quais o ser humano desenvolve uma identidade, cria símbolos e se abre para a diversidade de um mundo de Outros (2009, p. 65)

Em seus estudos e discussões, Moscovici advoga, para a Psicologia social, a necessidade de se dar atenção acentuada à produção e ao pensamento dos sociólogos e antropólogos para o estudo e a compreensão dos fenômenos psíquicos.

A superação dos dualismos clássicos (sujeito/ objeto, indivíduo/sociedade, individual/ coletivo, experimental/não experimental e bons e maus métodos) é um dos objetivos de Moscovici na formulação e no desenvolvimento da teoria das representações sociais (Moscovici, 2009). Guareschi e Jovchelovitch colocam que,

com a teoria das representações sociais, temos uma história diferente, que questiona ao invés de adaptar-se, e busca o novo, lá mesmo onde o peso hegemônico do tradicional impõe as suas contradições (...), e a teoria das representações sociais vai buscar, tanto dentro da Psicologia como fora dela, as possibilidades de reconstrução teórica, epistemológica e metodológica a que se propõe. É o caráter dessa busca que lhe faz ser tanto uma teoria específica da Psicologia social como um empreendimento interdisciplinar (2009, p. 17)

A teoria das representações sociais se coloca contra uma epistemologia individualista, do sujeito puro, ou uma epistemologia do objeto puro, focalizando seu olhar sobre a relação entre ambos, demonstrando que tanto o mundo como o sujeito são construídos por meio da relação dialética entre a atividade deste e a relação objeto-mundo. Segundo Guareschi e Jovchelovitch, a principal ruptura proporcionada pela teoria à Psicologia social refere-se ao individualismo teórico, que marcou a maioria das conceptualizações presentes na disciplina.

Quando se trata de representações sociais, portanto, a análise desloca-se para o nível social, ou seja, para os fenômenos produzidos pelas construções particulares da realidade social, e não para o sujeito individual; contudo, isso não consiste em, simplesmente, abandonar o âmbito individual, por se tratar de uma perspectiva individualista, mas em analisar o social como totalidade, considerando-se que esse social não se restringe à dinâmica de um agregado de indivíduos.

Para Jovchelovitch (2000), a construção das representações sociais está concentrada nos processos de comunicação e de vida, a que a autora denomina processos de mediação social, uma vez que, para ela, toda comunicação é mediação entre um mundo de perspectivas diferentes, podendo-se concluir que as representações sociais não só se formam por meio das mediações sociais como também elas próprias são mediações sociais. 
Sawaia (1995) sustenta que Moscovici criou o conceito de representação social com o objetivo de dar ênfase à visão do sujeito ativo e criativo na sociedade, de forma oposta à passividade em que foi reduzido o ser humano pela teoria cognitivista, sublinhando a função simbólica e dotada de poder de construção do real do aparelho cognitivo.

Encontra-se, em Jodelet, uma caracterização de representação social com a qual, segundo ela, a comunidade científica está de acordo:

(...) É uma forma de conhecimento, socialmente elaborada e partilhada, com um objetivo prático, e que contribui para a construção de uma realidade comum a um conjunto social. Igualmente designada como saber de senso comum ou ainda saber ingênuo, natural, essa forma de conhecimento é diferenciada, entre outras, do conhecimento científico. Entretanto, é tida como um objeto de estudo tão legítimo quanto este, devido à sua importância na vida social e à elucidação possibilitadora dos processos cognitivos e das interações sociais (2001, p. 22)

No entender de Guareschi, o conceito de representação social evidencia várias dimensões, devendo ser levado em consideração "(...) o que forma as representações sociais, como elas se constituem e quais os efeitos dessas representações", apontando, assim, um conceito: “(...) dinâmico, gerador (generativo), relacional, amplo, políticoideológico (valorativo) e, por isso tudo, social" (2009, p. 203).

O elemento social na teoria das representações sociais funciona como algo que as constitui, não havendo uma separação substancial, não determinando a pessoa, mas sendo parte integrante dela. Segundo a teoria, o ser humano é essencialmente social.

Wagner salienta que o conceito de representação social é multifacetado, já que a representação social pode ser concebida como um processo que envolve comunicação e discurso, através do qual significados e objetos são construídos e elaborados, e que, por outro lado, envolve o conteúdo de pesquisas orientadas empiricamente, nas quais as representações sociais são “(...) operacionalizadas como atributos individuais como estruturas individuais de conhecimento, símbolos e afetos distribuídos entre pessoas em grupos ou sociedades" (2009, p. 149).

A teoria das representações sociais entende que uma realidade social é criada apenas quando o novo ou o não familiar é incorporado aos universos consensuais, operando-se, nesse momento, os processos pelos quais ele passa a ser familiar, perde a novidade, tornando-se socialmente reconhecido e real. Pode-se dizer, dessa forma, de acordo com Jodelet, que “(...) nos interessamos por uma modalidade de pensamento, sob seu aspecto constituinte - os processos - e constituído - os produtos e o conteúdo, modalidade de pensamento cuja especificidade vem de seu caráter social" (2001, p. 22).

$\mathrm{Na}$ aludida teoria, as representações sociais evidenciam a necessidade de transformação do não familiar em familiar, e compõem-se de informações, ou seja, de organização dos conhecimentos que um grupo possui acerca de um objeto social, de atitudes, por meio da orientação quanto ao objeto, e campo, constituindo-se, assim, os universos consensuais. Conforme Constantino et al.,

as representações sociais são produzidas dentro de um discurso ideológico, manifestandose na vida cotidiana e no pensamento do homem, e a desalienação só é possível mediante uma ruptura do cotidiano. Para que ocorra a desalienação, torna-se necessária a desfamiliarização dos conceitos que estão transformados em crenças e não permitem a construção de novos conceitos. Surge a necessidade de problematizar a noção de realidade e de mudança de perspectiva sobre a vida (2007, p. 55) 
Jovchelovitch compara a objetivação e a ancoragem aos processos de condensação e de deslocamento, pois, para ela, objetivar é condensar significados diferentes em uma realidade familiar, e, assim fazendo, os sujeitos sociais ancoram o desconhecido em uma realidade conhecida e institucionalizada, deslocando, paradoxalmente, a existência dos significados já estabelecidos, que a sociedade, na maioria das vezes, luta para manter.
A teoria das representações sociais trabalha com dois processos sociocognitivos que atuam dialeticamente na formação das representações sociais, quais sejam: a ancoragem e a objetivação.

A ancoragem é o processo através do qual o indivíduo integra o que é estranho, sejam ideais, sejam acontecimentos, relações, objetos ou acontecimentos, etc., a um sistema de pensamento social preexistente, cujas antigas representações acolhem as novas, levando o não familiar a se tornar familiar (Farr, 2009). A ancoragem, por isso, consiste na aproximação do sujeito ao objeto, entre os indivíduos e os membros de determinado grupo a que ele pertence, fortalecendo a identidade grupal.

Na objetivação, as noções abstratas são transformadas em algo concreto, visível, materializando-se a palavra. Objetivar significa reproduzir o conceito de uma imagem, transformar noções, ideias, imagens etc., em coisas concretas, em realidade. Todavia, na identificação dos processos pelos quais os indivíduos descrevem, explicam e compreendem o mundo, devem ser considerados os fatos como construções sociais, não se podendo desprezar o contexto histórico e social em que estão inseridos. Moscovici afirma: "Numa palavra, a objetivação transfere a ciência para o domínio de ser e a ancoragem a delimita ao domínio do fazer, a fim de contornar o interdito da comunicação" (1978, p. 174).

Jodelet apresenta três fases para a objetivação: "1) seleção da descontextualização de elementos da teoria em função de critérios culturais normativos, 2) formação de um núcleo figurativo a partir dos elementos do núcleo conceitual e 3) naturalização dos elementos do pensamento, tornando-se elementos da realidade para o conceito" (2001, p. 41).
A objetivação e a ancoragem são, de acordo com Jovchelovitch, "(...) formas específicas em que as representações sociais estabelecem mediações, trazendo para um nível quase material a produção simbólica de uma comunidade e dando conta da concreticidade das representações sociais na vida social" (2009, p. 81).

Jovchelovitch compara a objetivação e a ancoragem aos processos de condensação e de deslocamento, pois, para ela, objetivar é condensar significados diferentes em uma realidade familiar, e, assim fazendo, os sujeitos sociais ancoram o desconhecido em uma realidade conhecida e institucionalizada, deslocando, paradoxalmente, a existência dos significados já estabelecidos, que a sociedade, na maioria das vezes, luta para manter.

A teoria das representações sociais trata, pois, do estudo do conhecimento do senso comum, de uma ampliação do olhar das fronteiras da ciência, para considerar também o conhecimento comum do homem como fonte do conhecimento legítimo e propulsor das transformações sociais.

\section{Críticas à teoria das representações sociais}

Apesar da importância e do avanço dos estudos desenvolvidos pela teoria, ao romper a dicotomia entre objetividade e subjetividade e ao possibilitar a apreensão dos fenômenos psicológicos em sua dimensão social, as críticas a ela não são poucas.

Uma delas é que, segundo Constantino et al, por se tratar do estudo do conhecimento do senso comum, a teoria das representações sociais “(...) corre o risco de ser diluída nos fenômenos culturais e ideológicos, uma vez que está presente na comunicação informal da vida cotidiana e em uma diversidade de assuntos que permeiam as relações interpessoais" (2007, p. 54). 
A despeito de tal crítica, Spink, lastreada nos estudos de Jodelet, apresenta a ideia de que as representações sociais são formas de conhecimento, e, como tal, são estruturas cognitivo-afetivas, não podendo, por isso, serem reduzidas apenas ao seu conteúdo cognitivo, sendo necessário, ainda, que seu entendimento seja efetuado com base no contexto que as elabora e “(...) a partir de sua funcionalidade nas interações sociais do cotidiano" (2009, p. 118).

Os processos de objetivação e de ancoragem na formação das representações sociais devem levar em conta seu contexto de produção, e devem ser sempre remetidos às condições sociais que os engendram. Porém, para a Psicologia social, de acordo com Spink, o importante, o objeto de estudo das representações sociais, na perspectiva psicossocial, é “(...) a atividade de reinterpretação contínua que emerge do processo de elaboração das representações no espaço de interação" (2009, p. 121).

Ademais, o contexto social pode remeter à justaposição de dois conteúdos que circulam na sociedade: o socio-histórico, que se refere aos construtos sociais que alimentam a subjetividade, e o discurso, como versões funcionais constituintes das relações sociais, os quais, ao interagirem, formam as representações sociais, privilegiando a descrição e o dado imediato.

Exatamente por se constituir na interação entre o socio-histórico e o discurso, considerando que o elo entre indivíduo e sociedade deve ser buscado não em um ou em outro, mas na produção conjunta e interativa de ambos, Gonçalves (2005) adverte que o método utilizado pela teoria das representações sociais desconsidera o caráter ideológico das representações sociais, privilegiando a descrição e o dado imediato.

Cumpre anotar que a afirmação apresentada por Gonçalves (2005) será discutida a seguir, e, desde já, registre-se que a teoria das representações sociais não se utiliza de um único método, mas de diversos, como se pode constatar na tese de doutorado de Moscovici (La Psychanalyse, son Image et son Public - 1961).

Nessa crítica, Gonçalves se vale, como pano de fundo, da teoria socio-histórica, baseada em Vygotsky, na qual a formação da subjetividade do indivíduo é materializada pela relação dialética entre o singular-particular-universal, isto é, o indivíduo interioriza os conceitos e as percepções socioculturais universais presentes no meio social, que foram acumulando-se ao longo de sua história, e desenvolve um processo de síntese dialética com sua história pessoal.

Para Constantino et al., a metodologia desenvolvida por Vygotsky prioriza a “(...) busca das origens e o curso do desenvolvimento das funções psicológicas superiores, ou seja, a gênese e a natureza dos processos psicológicos, partindo de um contexto histórico determinado" (2007, p. 46).

Desse modo, a crítica comparativa entre a teoria das representações sociais e a teoria socio-histórica, apresentada por Gonçalves (2005) e por Constantino et al. (2007), repousa, em resumo, na desconsideração, pela teoria das representações sociais, do caráter ideológico das representações sociais, formado ao longo de um contexto históricosocial do indivíduo, considerado apenas como fator de justaposição.

Mostra-se fundamental, portanto, a preocupação em vincular a ideologia ao estudo das representações sociais, conforme salientado pelo próprio Moscovici (2003, 2009) e por outros autores, como Guareschi (2009). 
Sawaia (1995) enfatiza que alguns estudiosos da obra de Moscovici, como Doise e Jahoda, se equivocaram ao declarar que, após Moscovici ter indicado a ideologia como objeto central dos estudos da Psicologia social, pouco se reportou a ela, em seus estudos posteriores, dela se afastando em prol da teoria das representações sociais.

Moscovici assim se posiciona: “(...) a Psicologia social é a ciência dos fenômenos da ideologia (cognição e representações sociais) e dos fenômenos da comunicação" (1985 como citado em Guareschi, 2009, p. 199).

Malgrado as críticas mencionadas, para Franco, as representações sociais são "(...) elaborações mentais construídas socialmente, a partir da dinâmica que se estabelece entre a atividade psíquica do sujeito e o objeto do conhecimento" (2004, p. 171). Tal relação, acrescenta o autor, ocorre na prática social e histórica da humanidade, e generaliza-se pela linguagem.

Mazzotti complementa a contextualização feita por Franco:

Para Moscovici, sujeito e objeto não são
funcionalmente distintos, eles formam um
conjunto indissociável. Isso quer dizer que
um objeto não existe por si mesmo, mas
apenas em relação a um sujeito (indivíduo
ou grupo); é a relação sujeito-objeto que
determina o próprio objeto. Ao formar sua
representação de um objeto, o sujeito, de
certa forma, o constitui, o reconstrói em
seu sistema cognitivo, de modo a adequá-
lo ao seu sistema de valores, o qual, por sua
vez, depende de sua história e do contexto
social e ideológico no qual está inserido (2002,
p. 171)

Para Chauí (1991), um dos traços fundamentais da ideologia reside na formação de um imaginário de que as teorias existem em si e por si, consistindo em abstrações criadas para a explicação da realidade, independentemente das características histórico-sociais presentes nessa realidade.
Ao explicitar a diferença entre a teoria das representações sociais e a teoria da atribuição, Guareschi indica um caminho interessante para se superar a crítica sobre a desconsideração da ideologia, salientando que “(...) a realidade mostra que toda explicação depende primariamente da idéia que nós temos da realidade. É essa idéia que governa nossas percepções e inferências construídas a partir delas, junto com nossas relações sociais" (2009, p. 197).

Na perspectiva de Sawaia (1995), na compreensão do conceito de ideologia elaborado por Moscovici, é preciso retomar seus estudos sobre a representação social da psicanálise, nos quais ele descreve três fases de evolução desse conhecimento: a fase científica (criação da teoria), a fase representacional (sua difusão e a criação de representações sociais) e a fase ideológica (a apropriação e o uso dessa realidade por um grupo ou instituição). "Ao ser apropriado, ele se reifica, se torna discurso estruturado e estruturante, impondo uma ordem estabelecida como natural" (Guareschi, 2009, p. 199).

Sawaia destaca que "o termo ideologia é usado para o conjunto de representações que se torna partilhado coletivamente pela reificação por meio da sua apropriação por órgãos estatais ou escolas de pensamento, e não pelo consenso e interação, subordinando o segundo ao primeiro" (1995, p. 78).

O conceito crítico de ideologia, fixado por Moscovici, desmistifica a possível neutralidade e ingenuidade do processo cognitivo, levando-o a apresentar-se como mediação nas relações de dominação e de exploração socioeconômicas, segundo o conceito marxista de ideologia. Isso leva a crer, com base em Sawaia, que as representações de um indivíduo não são independentes, mas estão relacionadas com a concepção de ser humano e de sociedade de cada um, desse 
modo, relacionam-se a outros sistemas de representação e expressam um discurso sobre a sociedade inteira.

De acordo com Guareschi (2009), Spink (1992) observa que o estudo das representações sociais pode ser divido em dois aspectos centrais, quais sejam: a construção de conhecimentos, na qual se inclui as condições socio-históricas que os concebem e sua elaboração sociocognitiva, e a funcionalidade desses conhecimentos na instauração, ou manutenção, das práticas sociais.

Apesar das críticas e das discussões que emergem das relações entre ideologia e representações sociais, concorda-se com Guareschi:

Cada uma dessas perspectivas empíricas demanda uma concepção de ideologia: a primeira, quando as RS são focalizadas como campos socialmente estruturados, leva à conceituação de ideologia como visão de mundo; a segunda, privilegiando as práticas sociais, possibilita a emergência da ideologia como 'representações hegemônicas a serviço das relações de poder'. As RS são, por isso, sempre ideológicas (2009, p. 201)

Por conseguinte, tendo em vista que as representações sociais se encontram em constante construção, porque constituem realidades dinâmicas, e não estáticas, que são elaboradas e modificadas dia após dia, enriquecidas e ampliadas com novos elementos e relações, conclui-se pela possibilidade de se separar a dimensão valorativa de seus processos de formação e de suas próprias estruturas, o que as torna, conforme Guareschi (2009), sempre ideológicas.

Constantino et al. ressaltam que

as transformações do homem e a forma como assimila a realidade social são percebidas pela teoria das representações sociais em um processo histórico e não natural, considerando a ideologia como determinante de formas de pensar e agir. A ideologia integra também essas representações e influencia diretamente na consciência individual, em que se identificam e se localizam. (...) A ideologia se concretiza em nível de representações sociais e é expressa no exterior, no mundo, pelas ações e linguagem dos homens (2007, p. 54)

Nesse sentido, não é verdadeira a premissa de que a teoria das representações sociais desconsidere o caráter ideológico das representações sociais, formado ao longo de um contexto histórico-social do indivíduo, pois a ideologia é considerada não apenas como fator de justaposição, mas de sobreposição.

A afirmação de Moscovici (2003) de que o importante não é conhecer as representações de um passado remoto, de sociedades primitivas, mas sim, as do tempo presente da sociedade, pois o conhecimento produzido é relativo a quem fala e de onde fala, a qual grupo pertence - e não do objeto em si, ao salientar a importância do grupo de pertencimento -, não significa, como já discutido, afastamento e desprezo pela ideologia nas representações sociais.

É pacífico que as representações sociais devem sempre ser remetidas ao contexto de produção; como psicólogos sociais, o contexto é importante, porque sem ele não é possível compreender as construções dele originadas, uma vez que a atividade de reinterpretação que nasce do processo de elaboração das representações no espaço de interação apresenta-se como principal objeto de estudo dos psicólogos sociais (Spink, 1995)

\section{Considerações finais}

Tratar de representações sociais significa abordar a própria construção da realidade, como universo em que se encontram 
indivíduos e grupos que se comunicam, se relacionam e consolidam o meio social em que vivem.

Essa dinâmica tem seu lugar no cotidiano dos indivíduos, em suas atividades diárias, como nas reuniões públicas, nos cafés, nas ruas, nos meios de comunicação, nas instituições sociais, enfim, no encontro público de atores sociais, em todos os espaços em que sujeitos se reúnem para falar e dar sentido ao cotidiano (Jovchelovitch, 2000). Em todos esses encontros ou interações, são colocados em jogo elementos ideológicos, emocionais, cognitivos, institucionais - tudo aquilo que diz respeito ao humano em sua plenitude. Tratase de considerar as condições sociológicas e psicológicas em uma perspectiva dinâmica. As representações sociais, segundo Jodelet, não são mera reprodução dos objetos, pois implicam uma atividade criativa e interpretativa dos sujeitos.

Para Moscovici, há um poder criador de objetos e eventos da atividade representativa, há “(...) relações entre o nosso reservatório (...) de imagens e a nossa capacidade de combiná-las, de engendrar novas e surpreendentes combinações". O autor continua:

(...) a representação constitui uma preparação para a ação, pois, além de guiar o comportamento, ela remodela e reconstitui os elementos do meio ambiente em que o comportamento deve se ligar. Ela consegue incutir um sentido ao comportamento, integrá-lo numa rede de relações em que está vinculada ao seu objeto, fornecendo ao mesmo tempo as noções, as teorias e os fundos de observação que tornam essas relações estáveis e eficazes (2003, p. 49)

A investigação, levando em conta a perspectiva das representações sociais, propõe uma aproximação possível do conhecimento prático, produzido no universo do senso comum, que são as teorias elaboradas no cotidiano das interações entre os indivíduos, para explicar a realidade vivida.
Para Jovchelovitch,

quando nós falamos em representações sociais, a análise desloca-se para um outro nível; ela já não se centra no sujeito individual, mas nos fenômenos produzidos pelas construções particulares da realidade social. Assim, o problema não está em abandonar o indivíduo porque ele implica necessariamente uma perspectiva individualista. Ao contrário, o problema central é reconhecer que, ao analisar fenômenos psicossociais - e representações sociais - é necessário analisar o social como totalidade. Isso quer dizer que o social envolve uma dinâmica que é diferente de um agregado de indivíduos (2009, p. 79)

A teoria das representações sociais, conforme Carvalho permite "um contraponto à compreensão que a sociedade moderna tem a respeito da introdução do novo" (2001, p. 59), pois o estudo das representações sociais proporciona o acesso, a identificação de conhecimentos que "determinado grupo desenvolveu sobre uma nova realidade, como os simboliza, de modo a transformá-los em algo familiar que permita a interação de seus pares e a comunicação entre eles, bem como com outras pessoas ou grupos" (2001, p. 59).

Anote-se que trabalhar com a teoria das representações sociais é apaixonante e desafiador; apaixonante, uma vez que propicia a expectativa de abordar o objeto de pesquisa em sua integridade; de acordo com Souza, "desafiante, porque a noção é de natureza transversal e psicossocial, e busca reunificar na leitura da realidade aspectos de natureza científica diversa: ideológica, histórica, sociológica, psíquica, etc" (2005, p. 62).

Jodelet (2001) assinala que o campo de pesquisa em representações sociais apresenta três características marcantes: a vitalidade, a transversalidade e a complexidade. Tais características demonstram o dinamismo 
dos estudos e das pesquisas que envolvem as representações sociais, o que pode ser destacado como uma de suas peculiaridades.

Sua vitalidade se deve ao fato de que a noção de representação social tem sido empregada em várias correntes de pesquisa, atestada pela quantidade de publicações, e, ainda, conforme Jodelet, pela “(...) diversidade de países onde ela é empregada, dos domínios onde é aplicada, pelas abordagens metodológicas e teóricas que inspira" (2001, p. 23).

Já a transversalidade se dá devido à posição em que se encontra o conceito de representação social, isto é, ela está situada na interface entre o aspecto psicológico e o social, noção que desperta o interesse de todas as ciências humanas, sendo encontrada em Sociologia, Antropologia e História, e também estudada em suas relações com a ideologia, com os sistemas simbólicos e as atitudes sociais refletidas pelas mentalidades.

Conforme coloca Jodelet, "essa multiplicidade de relações com disciplinas próximas confere ao tratamento psicossociológico da representação um estatuto transverso que interpela e articula diversos campos de pesquisa, reclamando não uma justaposição, mas uma real coordenação de seus pontos de vista" (2001, p. 25).

Além disso, a autora ressalta que a teoria deve ser desenvolvida em uma abordagem que respeite a complexidade dos fenômenos e da noção, mesmo diante do grande desafio que isso representa, complexidade que se reflete tanto na diversidade de métodos que vêm sendo empregados nas pesquisas relacionadas à teoria como nos objetos pesquisados sob seus pressupostos e na amplitude desses objetos.

A teoria das representações sociais pressupõe uma tentativa de ruptura com as vertentes clássicas das teorias psicológicas, propondo mudanças no posicionamento quanto ao estatuto da objetividade e da busca da verdade, apresentando-se, assim, como alternativa para pesquisadores e teóricos. 


\section{Luis Fernando Rocha}

Doutor em Psicologia (Área do Conhecimento: Psicologia e Sociedade) pela Faculdade de Ciências e Letras de Assis - Universidade Estadual Paulista - UNESP. Promotor de justiça do Estado de São Paulo e professor da Universidade Paulista, Assis -SP - Brasil.

Email: rocha.l@ig.com.br

Endereço para envio de correspondência:

Rua Sebastião Nogueira Leite, 170, Jardim Europa. CEP: 19.815-130. Assis, SP.

Recebido 09/01/2012, 1a Reformulação 30/05/2013, Aprovado 29/08/2013. 
Abbagnano, N. (1988). Dicionário de filosofia. São Paulo: Martins Fontes.

Alves-Mazzotti, A. J., \& Gewandsznajder, F. (2002). O método nas ciências naturais e sociais: pesquisa quantitativa e qualitativa (2a ed.). São Paulo: Pioneira.

Bachelard, G. (1968). O novo espírito científico. Rio de Janeiro: Tempo Brasileiro.

Carvalho, A. M. R. (2001). Privatização e demissão: representações sociais de ex-ferroviários. Dissertação de mestrado. Faculdade de Ciências e Letras, Universidade Estadual Paulista, Assis, SP.

Cervo, A. L., \& Bervian, P. A. (1996). Metodologia científica (4a ed.). São Paulo: Makron Books.

Chauí, M. (1991). O que é ideologia. São Paulo: Brasiliense.
Cohen, E., \& Franco, R. (1993). Evolución de proyetos sociales. Madrid: Siglo XXI.

Constantino, E. P., Eloy, C. B, Quadrini, E.T., \& Macedo, L. M. (2007). O método histórico-dialético: contribuições da teoria das representações sociais e da psicologia sócio-histórica. In E. P. Constantino (Org.), Percursos da psicologia qualitativa em psicologia (pp. 39-60). São Paulo: Arte \& Ciência.

Durkheim, E. (1978). As regras do método sociológico. São Paulo: Abril.

Farr, R. M. (2009). Representações sociais: a teoria e sua história. In P. Guareschi \& S. Jovchelovitch (Orgs.), Textos em representações sociais (11a ed., pp. 31-59). Petrópolis, RJ: Vozes. 
Ferreira, F. R., Calvoso, G. G., \& Gonzales, C. B. L. (2002). Caminhos da pesquisa e a contemporaneidade. Psicologia: Reflexão e Crítica, 15(2), 243-250. doi: http://dx.doi. org/10.1590/S0102-79722002000200002

Feyerabend, P. (2007). Contra o método. São Paulo: UNESP.

Franco, M. L. P. B. (2004). Representações sociais, ideologia e desenvolvimento da consciência. Cadernos de Pesquisa, 34(121), 169-186. doi: http://dx.doi.org/10.1590/S010015742004000100008

Gonçalves, M. G. M. (2005). O método de pesquisa materialista histórico e dialético. In A. A. Abrantes, N. R. Silva \& S. T. F. Martins. Método histórico-social na psicologia social (pp. 86-104). Petrópolis, RJ: Vozes.

Guareschi, P. A. (1996). Representações sociais: alguns comentários oportunos. In C. M. Nascimento-Schulze (Org.). Novas contribuições para teorização e pesquisa em representação social (pp. 9-35). Florianópolis, SC: Coletâneas da ANPEPP 10.

Guareschi, P. A. (2003). Pressupostos metafísicos e epistemológicos na psicologia. Psicologia: Reflexão e Crítica, 16(2), 245-255. doi: http://dx.doi.org/10.1590/S0102-79722003000200004

Guareschi, P. A. (2009). Sem dinheiro não há salvação: ancorando o bem e o mal entre neopentecostais. In P. Guareschi, S. \& Jovchelovitch, S. (Orgs.), Textos em representações sociais (11a ed., pp. 191-225). Petrópolis, RJ: Vozes.

Guareschi, P. A., \& Jovchelovitch, S. (2009). Textos em representações sociais (11a ed.). Petrópolis, RJ: Vozes.

Jodelet, D. (2001). Representações sociais: um domínio em expansão. In D. Jodelet (Org.), As representações sociais (L. Ulup, trad., pp. 17-44). Rio de Janeiro: Ed. UERJ (Trabalho original publicado em 1989).

Jovchelovitch, S. (2000). Representações sociais e esfera pública: a construção simbólica dos espaços públicos no Brasil. Petrópolis, RJ: Vozes.

Jovchelovitch, S. (2009). Vivendo a vida com os outros: intersubjetividade, espaço público e representações sociais. In P. Guareschi, S. \& Jovchelovitch, S. (Orgs.), Textos em representações sociais (11a ed., pp. 63-85). Petrópolis, RJ: Vozes.

Köche, J. C. (1997). Fundamentos de metodologia científica: teoria da ciência e prática da pesquisa (15a ed.). Petrópolis, RJ: Vozes.

Kuhn, T. (1975). A estrutura das revoluções científicas. São Paulo: Perspectiva.

Kuhn, T. (2006). O caminho desde a estrutura: ensaios filosóficos, 1970-1993, com uma entrevista autobiográfica. São Paulo: UNESP.

Mazzotti, A. J. A. (2002). A abordagem estrutural das representações sociais. Psicologia da Educação, (14/15), $17-37$.

Mendonça, A. L. O., \& Videira, A. A. P. (2002). A revolução de Kuhn. Ciência Hoje, (189), 77-79.

Menin, M. S. (2000). Representações sociais de lei, crime e injustiça em adolescentes. Tese de Livre-Docência em Psicologia. Faculdade de Ciências e Tecnologia, Universidade Estadual Paulista, Presidente Prudente, SP.

Moreira, A. S. P., \& Oliveira, D. C. de. (1998). Estudos interdisciplinares de representação social. Goiânia, GO: AB.

Moreira, D. A. (2002). O método fenomenológico na pesquisa.
São Paulo: Pioneira Thomson.

Moscovici, S. (1978). A representação social da psicanálise (A. Cabral, trad.). Rio de Janeiro: Zahar (Trabalho original publicada em 1961).

Moscovici, S. (1985). Psicologia social. Barcelona: Paidós.

Moscovici, S. (2003). Representações sociais: investigações em psicologia social (P. A. Guareschi, trad.). Petrópolis, RJ: Vozes (Trabalho original publicado em 2000).

Moscovici, S. (2009). Representações sociais: investigações em psicologia social. Petrópolis, RJ: Vozes.

Sá, C. P. (1995). Representações sociais: o conceito e o estado atual da teoria. In M. J. Spink (Org.), O conhecimento no cotidiano. As representações sociais na perspectiva da psicologia social (pp. 19-45). São Paulo: Brasiliense.

Santos, B. de S. (1988). Um discurso sobre as ciências na transição para uma ciência moderna. Estudos Avançados, 2(2), 56-71. doi: http://dx.doi.org/10.1590/S0103-40141988000200007

Sawaia, B. B. (1995). Representação e ideologia - o encontro desfetichizador. In M. J. Spink (Org.), O conhecimento no cotidiano. As representações sociais na perspectiva da psicologia social (pp. 73-84). São Paulo: Brasiliense.

Severino, A. J. (1996). Dilemas e tarefas das ciências humanas frente ao pluralismo epistemológico contemporâneo. Interações - Estudos e Pesquisas em Psicologia, I(1), 97-115.

Severino, A. J. (2000). O sujeito, a história e a educação: tarefas e identidade da filosofia da educação. Tese de Livre-Docência, Faculdade de Educação, Universidade de São Paulo, São Paulo, SP.

Severino, A. J. (2002). Pós-graduação e pesquisa: o processo de produção e de sistematização do conhecimento no campo educacional. In L. Bianchetti \& A. M. N. Machado. A bússola do escrever - desafios e estratégias na orientação de teses e dissertações (pp. 67-87). Florianópolis, SC: Editora da UFSC; São Paulo: Cortez.

Souza, D. B. (2005). Representações sociais sobre indisciplina em sala de aula dos professores iniciantes da rede municipal de Presidente Prudente-SP: implicações para a formação inicial. Dissertação de mestrado. Faculdade de Ciências e Tecnologia, Universidade Estadual Paulista, Presidente Prudente, SP.

Spink, M. J. (1995). O conhecimento no cotidiano: as representações sociais na perspectiva da psicologia social. São Paulo: Brasiliense.

Spink, M. J. (2009). Desvendando as teorias implícitas: uma metodologia de análise das representações sociais. In P. Guareschi, S., \& Jovchelovitch, S. (Orgs.), Textos em representações sociais (11a ed., pp. 117-145). Petrópolis, RJ: Vozes.

Wagner, W. (2009). Descrição, explicação e método na pesquisa das representações sociais. In P. Guareschi, S. \& Jovchelovitch, S. (Orgs.), Textos em representações sociais (11a ed., pp. 149-186). Petrópolis, RJ: Vozes. 